\title{
Information Users and Usability in the Digital Age
}

Review: G.G. Chowdhury, Sudatta Chowdhury, 2011, Facet Publishing, London $£ 39.95$ (hardcover)

\author{
George Macgregor \\ Information Services \\ University of Strathclyde
}

It is no accident that interest in human-computer interaction $(\mathrm{HCl})$ over recent decades has coincided with the proliferation of ICT, such that it has grown into a fully-fledged sub-discipline of the computer and information sciences and the behavioural sciences. The evolution of $\mathrm{HCl}$ reflects our need to better understand how humans and technology can interact in order to improve technological support for human activities. Perhaps the most active sub-branch of $\mathrm{HCl}$ is usability; and it is this topic which forms the broad focus of Information Users and Usability in the Digital Age.

The body of literature concerning usability is crowded, encompassing practitioner guides, student textbooks and research papers. Most usability principles and issues are admirably addressed by Shneiderman et al. (2009) or by Nielsen and Loranger (2006), the latter of whom was recently described by Businessweek as one of the world's most "influential designers" (Walters, 2010). Even older texts that communicate general usability principles, such as Nielsen's Usability Engineering (Nielsen, 1994), remain indispensable, seminal contributions to the usability canon. It is therefore apposite to ask oneself whether another book on usability is actually required.

As good as most of the key usability texts are, they often emphasise the technical measures or the design principles to be followed in order to achieve "good" usability, with little exploration of the underlying research on information seeking behaviour which often underpins much of usability thinking. Some literature can also conflate usability with user experience (UX), the latter of which focuses more on users' achievement of pragmatic, hedonic goals and/or emotional responses such as pleasure (Bevan, 2008), rather than on usability itself.

Information Users and Usability in the Digital Age addresses many of these aforementioned failings by - as its title suggests - explicitly examining information users and all the related topics therein. The twin concerns of "information users" and "usability" are reflected in the structure of the book, with the first three chapters dealing exclusively with information user issues and the remaining seven exploring usability topics. This may appear a little lopsided but it is worth noting that the "information user" chapters are detailed. Indeed, a cursory glance at the contents page appears to suggest that they account for circa 45 percent of the total wordage. Chowdhury and Chowdhury use these opening three chapters to introduce the concepts of information users and usability, information needs, user studies, information seeking behaviour and associated information seeking behaviour models, and information retrieval, to mention but a few topics. The authors also discuss "new" information seeking behaviour models, including one proposed by the authors themselves. Usability is explored in detail, as are the topics of web usability, user-centred design, accessibility and heuristic evaluation. Chapters on conducting usability inspection studies and the implications for usable design in an information world where the digital divide and digital immigrant-natives abound are also included.

Although furnishing the reader with the theoretical issues pertaining to information users and usability, Information Users... also adopts a practical focus. This is particularly obvious from some usability chapters. For example, chapter five focuses almost exclusively on selecting suitable usability study participants, while another (chapter six) moves into research methods territory by delineating 
typical usability metrics and data analysis considerations, such as data types and statistical tests. It is unlikely that the latter chapter would meet one's entire information need within the realm of statistics, but it does add to the perception that Information Users... would be a particularly useful "handbook" for those slaving at the usability coalface.

In many ways this book delivers a generalist view of information users and usability, thus reflecting the multifarious media and numerous information consumption contexts that exist today. And this immediately makes Information Users... potentially relevant to a wide audience within the information related professions. Curious, however, is the inclusion of a chapter on the usability of digital libraries (chapter eight), which appears to deviate from this generalised theme. Its inclusion, however, only remains curious until one explores the research background of the authors; and although jarring slightly with the overall tone of the book, the digital library focus provides a valuable usability case study of issues within a domain which is not simply another e-commerce web site.

G.G. Chowdhury is Director of the Centre for Information and Knowledge Management and Sudatta Chowdhury is a Lecturer in Information and Knowledge Management, both at the University of Technology, Sydney. It is perhaps as a result of their academic experience that they have delivered a book that is both accessible and builds on the extant usability and information seeking literature.

And although Information Users... is inevitably lighter on usability detail than the books of Nielsen or the tomes of Shneiderman, Chowdhury and Chowdhury's contribution is well-rounded and informed by extensive use of the research literature (all of which is listed at the end of every chapter). Information Users... is therefore a recommended for the postgraduate student and new usability practitioner alike.

\section{References}

Bevan, N. (2008), "Classifying and selecting UX and usability measures", in Law, E.L.-C., Bevan, N., Christou, G., Spingett, M. and Lárusdóttir, M. (Eds), International Workshop on Meaningful Measures: Valid Useful User Experience Measurement (VUUM ), Reykjavik, 18 June, Institute of Research in Informatics of Toulouse, Toulouse, pp. 13-18, available at: www.cost.eu/library/publications/08-26-Meaningful-Measures-Valid-UsefulUser-Experience-Measurement-VUUM (accessed 6 January 2012)

Nielsen, J. (1994), Usability Engineering, Morgan Kaufmann, San Francisco, CA.

Nielsen, J. and Loranger, H. (2006), Prioritizing Web Usability, New Riders, Berkeley, CA.

Shneiderman, B., Plaisant, C., Cohen, M. and Jacobs, S. (2009), Designing the User Interface: Strategies for Effective Human-Computer Interaction, Addison-Wesley, London.

Walters, H. (2010), "The value of design", Businessweek, 1 February, available at: www.businessweek.com/innovate/content/feb2010/id2010021 071409.htm (accessed 6 January 2012). 